\title{
Covid 19 Küresel Salgın Sürecinde Kentsel Kamusal Alanlarda Güvenlik Algısının Değişimi
}

\author{
Züleyha Sara Belge ${ }^{1}$ \\ ORCID: 0000-0003-0500-4847
}

Öz

Covid-19 küresel salgın sürecinde değişen yaşam koşulları nedeniyle kamusal alanların kullanımı değişmektedir. Covid-19 önlemleri nedeniyle, kentlinin ekonomik, sosyal ve kültürel ihtiyaçların karşıladı̆̆ı kamusal alanlarda güvenlik anlayışı da bu bağlamda yeniden tanımlanmaktadır. Kentlerdeki açık alan büyüklükleri, kişiler arasındaki sosyal mesafenin sağlanması, maske kullanımı ve gerekli koşullarda kişilerin hastalı belirtileri açısından izlenebilmesi gibi önlemler kamusal alanın kullanımında değişime neden olmuştur. Bu durum, kent mekânlarının krizlere hazırlıklı olmadı̆̆ın ortaya koymaktadır. Covid-19 küresel salgin döneminde, kentsel kamusal mekânın değişmez bir birleşeni olan güvenlik parametresi, salgin dönemi öncesine göre farklı ölçütlerle değerlendirilmelidir.

Bu araştırma, kentsel kamusal mekânda değişen kullanıcı algısını ve güvenlik parametresini ortaya koymayı amaçlamaktadır. Çalışmanın ilk bölümünde yer, mekân ve değişen kentsel-kamusal mekân tanımlar incelenerek güvenlik kavramı tanımlanmaktadır. Çalı̧̧manın ikinci bölümünde niceliksel ve niteliksel ölçüm ve gözleme dayanan araştırma yöntemi yer almaktadır. Çalışma alanı olarak Mersin kentinin en büyük parkı olan Mersin Kıyı Parkında, küresel salgın süreci öncesinde olduğu kadar, Covid-19 önlemleriyle birlikte de en aktif kullanulan alanlardan biri olan Mersin Marina girişinin doğusunda kalan kıyı parkı alanı incelenmişstir. Çalışmanın son bölümünde araşttrmanin bulgularnna dayanarak Covid-19 sürecinde kentsel-kamusal mekânlarda kullanıcı davranışları esas alınarak kamusal alanda güvenlik ölçütleri ve güvenlik kavramına ilişkin öneriler sunulmaktadır.

Anahtar Kelimeler: Güvenlik, Covid-19, Küresel Salgn, Kamusal Alan, Mersin

\footnotetext{
1 Öğr. Gör. Dr., Mersin Üniversitesi, E-mail: zbelge@mersin.edu.tr idealkent (c) Kent Araştırmaları Dergisi (Journal of Urban Studies) http://idealkentdergisi.com
}

Geliş Tarihi Received Date: 15.02.2021 Kabul Tarihi Accepted Date: 05.09.2021 


\title{
Changing Perception of Safety in Urban Public Space during Covid-19 Pandemic
}

\author{
Züleyha Sara Belge ${ }^{2}$ \\ ORCID: 0000-0003-0500-4847
}

\begin{abstract}
By the reason of pandemic precautions; the understanding of safety in public spaces has also changed. Precautions such as provision of social distance, use of masks, and ability to monitor people in terms of disease symptoms under necessary conditions have caused changes in the use of public space. This situation also revealed that urban spaces are not prepared for crises. In the Covid-19 period, the safety parameter, which is an invariable component of urban public space, should be evaluated with different criteria compared to the pre-pandemic period.

This study aims to reveal the changing user perception and safety parameter in urban public space. In the first part of the study, the concept of safety is defined by examining the definitions of place, space and changing public space. In the second part, the research method and observation tools are explained. As case study area, the coastal park in the east of Mersin Marina entrance, which is one of the most actively used areas with Covid-19 measures as well as before pandemic, is examined. In the last part, suggestions regarding safety parameter and concept of safety are presented based on user behaviour in urban-public spaces in the Covid-19 process.
\end{abstract}

Keywords: Safety, Covid-19, Pandemic, Public Space, Mersin.

\footnotetext{
2 Instructor Dr., Mersin University, E-mail: zbelge@mersin.edu.tr idealkent $\subset$ Kent Araştırmaları Dergisi (Journal of Urban Studies) 


\section{Giriş}

Kamusal alan, tarihsel olarak gelişen odaklardan çağdaş kullanımlara kadar geniş bir kullanım alanına sahiptir. Günlük pratikler, rutinler ve sosyal yaşam ile kamusal alanda birey olma deneyimi elde edilir. Kamusal alan tüm topluma aittir ve herkes tarafından çoğunlukla özgürce kullanılmaktadır. En geniş tanımıyla meydanlar, sokak ve kentsel açık alanlar-parklar kamusal alanlardır. Bu alanlara ek olarak, kamu binaları, eğitim tesisleri, sağlık tesisleri ve/veya sosyo-kültürel tesisler ile bahçeleri farklı kullanıc grupları için kamusal alan biçimleri olarak değerlendirilebilmektedir. Günümüzde çağdaş toplumun değişen ve çeşitlenen ihtiyaçları göz önüne alındığında, kamusal alan kavramı genişlemiştir. Alışveriş merkezlerinin açık ve kapalı alanlarının kullanım biçimleri üzerinden başlayan genişleme, günümüzde kafe ve restoran gibi yeme-içme mekânlarının da birlikte kullanılmasıyla ilişkilendirilmektedir. Bu nedenle, kamusal alan kavramı mülkiyet ve iyelik haklarından bağımsızdır. Kamuya ait olma değil kamusal alanın birlikte kullanılabilmesi ve sosyal pratik alanı olması önem taşımaktadır.

Kamusal alanın etkin kullanımında güvenlik kavramı ve algisı en temel ölçütlerden bir tanesidir. Taşıt trafiğinden yalıtılmış ve/veya taşıt trafiğinin etkileri için gerekli önlemlerin alınmış olması, çevresel faktörlerin olumsuz etkilerinin azaltılması (güneş-gölge, rüzgâr, yağmur, vb.) veya gece ışılandırmasının yeterliliği gibi fiziksel güvenlik ölçütlerine ek olarak, kullanıcıların kendilerini güvende hissetmelerini etkileyen etmenler de algılanan güvenlik ölçütleri olarak tanımlanmaktadır. Ancak, Covid-19 küresel salgın sürecinin ortaya çıkardığı riskler ve önlemler nedeniyle kamusal alanlarda güvenlik kavramında da değişimler izlenmiştir. Açık alanların kullanımına getirilen kısıtlamaların yanı sıra sosyal mesafe, maske ve temizlik koşulları ile ateş ölçümü gibi önlemler kamusal alanların kullanım biçimlerinde de değişime sebep olmuş̧tur. Bu nedenle, Covid-19 küresel salgın dönemi öncesinde belirlenen kamusal alanda güvenlik ölçütlerinin de yeniden gözden geçirilmesi yerinde olacaktır.

Bu çalışma kapsamında, kamusal alanda güvenlik ölçütlerinin değerlendirilebilmesi için örnek çalışma alanında gözleme ve karşılaştırmaya dayalı bir yöntem izlenilmiştir. Küresel salgın süreci öncesinde olduğu kadar, küresel salgın sürecinde de, sokağa çıkma izin saatlerinin sınırları içerisinde yoğun olarak kullanılan Mersin kıyı parkının, Marina çevresi örnek çalışma alanı olarak belirlenmiştir. Bu alanda küresel salgın süreci öncesinde yapılan gözlemler esas alınarak salgın sürecinde de kullanıcılara ilişkin yürütülen 
araştırma güvenlik algısındaki değişimlerin izlenebilmesini sağlamıştır. Çalışma sonucunda, bu gözlem ve analizler esas alınarak, planlama ve kentsel tasarımda kamusal alanın oluşumu konusunda öneriler geliştirilmiştir.

\section{Kamusal Alan ve Kamusal Alanda Güvenlik}

Bu bölümde, değişen kamusal alan kavramına ilişkin bir değerlendirme sonrasında, kamusal alanın kamusallığı, etkin kullanımı ve kullanıcılarının günlük rutin ve ritimlerine ilişkin tartısmalar sunulmaktadır. Daha sonrasında ise kamusal alanın oluşumunda belirleyici bir etmen olan güvenlik kavramına açılık getirilmektedir.

Kamusal alan tanımını kavrayabilmek için, yer ve mekân arasındaki farkı anlamak gerekir. Bu bağlamda, mekânın sosyal anlamları içinde barındıran bir konum / yer olduğundan söz edilebilir (Lefebvre, 1991). 'Kamu' ve 'Kamusal' alan kavramlarl; tüm insanlarla ilgili olmak, toplumun her bireyine açı olmak, herkes tarafından paylaşılabilmek, açık bir şekilde yapılabilmek ve herkes tarafından bilinmek anlamlarını taşımaktadır (Gove,1976; Markins, 1998 aktaran Akkar, 2012, s.176).

Kamusal alan insanlar arasındaki etkileşimde önemli bir role sahiptir. $\mathrm{Bu}$ anlamda yurttaş olmanın deneyimi kamusal alanda gündelik yaşam pratikleri, günlük rutinler ve toplumsal ilişkiler ile elde edilir. Toplumsal yaşam ve gündelik yaşam pratikleri mekânı üretirler. Bu bağlamda yerelin kendine özgü nitelikleri değişen coğrafya ve yerellik ile değer kazanmaktadır. Lefebvre (2014) ise mekânsal pratik, mekânın temsili ve temsilin mekânı trialektiği ile toplumsal mekânun toplumsal olarak üretildiğinden söz eder. Kamusal alan kentin kimliğinin ve karakterinin belirlenmesi için insanlar arasındaki etkileşimi sağlamada önemli bir role sahiptir. Günümüzde, ekonominin farklı biçimleri ve siyasi dinamikleri mevcut coğrafyayı yeni mekânlara dönüştürmekte, değiştirmektedir. Bu bağlamda, coğrafyadaki ve yerellikteki çeşitlilikler yerele özgü özelliklere değer katmaktadır. Farklı mekânsal referanslar ve ekonomik, sosyal veya politik değişimler ile bu farklılıklar ve çeşitlilikler mekânsal ifadenin değişimi dönüşümünü oluşturmaktadır. Bu döngü ekonomiyi, politikayı, sosyal yaşamı ve ilişkileri değiştirerek-dönüştürerek kamusal mekânı oluşturur. Bunlar her zaman etkileşim halindedir. Benzer bir çerçevede, Nasar (1989,s.37) mekânsal davranışın, insanların mekânı nasıl kullandıkları ve çevreyle ilişkilerini, ziyaretlerini, ziyaret zamanlarını, sıklıklarını veya bu tür yerlerden kaçınma şeklini ifade ettiğini belirtmektedir

Kentsel mekân, kamusal mekândan farklı olarak, farklı düzeylerde kamusallıkların (publicness) ve özelliklerin (privateness) olduğu alanlardan oluşur 
(Akkar, 2012). Kamusal alanların farklı düzeylerde kamusallı̆̆ı söz konusudur. Bu farklı düzeyler kamusal alanın sahip olduğu kaynakların, etkinliklerin ve bilgilerin açık ve erişilebilir olmasıyla ilişkilidir. Ayrıca, alanın kamusal bir otorite tarafından ne şekilde yönetildiğine ve denetlendiğine ve kamu yararına hizmet edip etmediğiyle de ilişkilidir (Akkar, 2005, Akkar, 2012).

Diğer yandan, Carmona, De Magalhaes ve Hammond (2008,s.43) değişen kentsel kamusal alan anlayışının günümüz kullanımları üzerine bir takım eleştirilerinden söz etmektedirler. İhmal edilmiş, kayıp, istila edilmiş-ihlal edilmiş ve ayrıcalıklı alanlar kavramları kamusal alanın fiziksel boyutunu ortaya koyan ifadelerdir. Bunlara ek olarak, kamusal alanda özelleştirme, yapım, tüketim veya ayrışma güncel söylem içinde değerlendirilen terimlerdir. Bu yaklaşım kamusal alanın doğaya ve kullanıcılara göre sınıflandırılmasını sağlar.

Bu tartısmalara ek olarak; sokaklar, parklar, meydanlar, kamuya ait kapalı alanlar; kütüphaneler, müzeler, kültür merkezleri ve bunların dışında özel mülkiyetli alanlar; üniversite kampüsleri veya spor alanları, alışveriş merkezlerinin iç ve dış mekânları veya gastronomik tesisler farklı kamusal alanlar olarak tanımlanmaktadır. Yarı kamusal alan (quasi public space), sözde kamusal alan (pseudo public space) ve üçüncü yerler (third places) diğer güncel tartı̧̧malar olarak karşımıza çıkmaktadır.

Bu bağlamda, kamusal alan üzerine yapılacak tartışmalarda kamusallık belirleyicidir (Akkar, 2005). Genel bir ifadeyle, kamu kavramı çerçevesinde herkese açık olmayı, erişilebilirliği veya tüm toplumla paylaşımı içinde barındırır (Gove, 1976; Markins, 1998 aktaran Akkar, 2005,s.2). Bu nedenle tüm topluma açık olması kamusal alanın tanımında önemli bir noktadır. Akkar ve Memlük (2015,s.196-198) kapsayıcı olarak mekânın erişilebilirliğini tartışmakta ve kamusal alanın kapsayıcılı̆̆ının farklı etkenlerinden bahsetmektedirler. Bilsel (2009) ise, günümüzde kitle iletişim araçları ile birlikte kamusal alanın her yerde olduğuna işaret etmektedir. Bu durumda, kamusal alan ile özel alan arasındaki sınır da belirsizleşmektedir.

Bu tartışmalar ise kamusal alanın niteliği ve kullanıcıların tercihlerinin kamusal alanın kamusallığını oluşturduğunu ortaya koymaktadır. Gehl (2010) açık alan aktivitelerini 3 temel grupta inceler. Bunlar gerekli (zorunlu) aktiviteler, isteğe bağlı (opsiyonel aktiviteler) ve sosyal aktivitelerdir. Birinci grup çalışma, eğitim veya çocuk bakımı gibi günlük ihtiyaçlar için yürüme, yemek yeme, bekleme veya alışveriş yapma aktivitelerini içerirken, ikinci grup uygun zamanda ve yerde yürüme, bakma, oturma, izleme veya koşma gibi isteğe bağlı aktiviteleri içerir. Son grup ise diğer insanların varlığın gerektiren sosyal 
ve kültürel faaliyetler olarak tanımlanabilir. Gehl (2010) diş mekân kalitesindeki bir artışın özellikle isteğe bağlı aktivitelere destek verdiğini belirtir. Bu bağlamda açık hava ve dış mekân aktiviteleri çevre ile değişen türler ve ilişkiler ile uzlaşır, ancak temelde kamusal alan olarak değerlendirilebilir (Şekil-1).

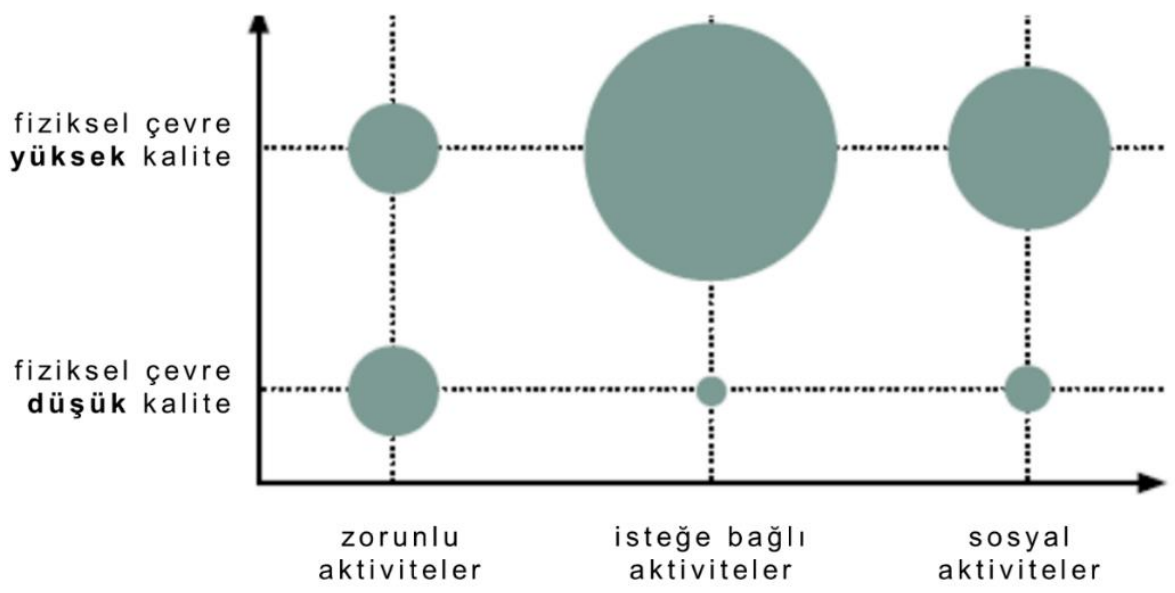

Şekil 1. Mekân kalitesi ve aktivite türleri arasındaki ilişki (Gehl, 2010, s.21).

Toplum için daha iyi yerler üretilmesi planlama ve kentsel tasarım ile mümkündür. Bu bağlamda iyi bir yerin tasarlanmasında yer duygusu (sense of place) öne çıkmaktadır. Kamusal alanın biçimi ve tasarımı, aktiviteler, faaliyetler, fiziksel ortam ve anlamla tanımlanan yer duygusuna dayanır (Montgomery, 1998). Bu boyutlar kentsel kamusal mekânda çeşitlilik, canlılık, sokak yaşamı, izleme, kafe kültürü, yerel etkinlikler ve gelenekler gibi farklı özellikler ve bileşenler içerir. Mekânın biçimi ile ilişkili olarak ölçek, yoğunluk ve geçirgenlik bileşenleri de söz konusudur. Bunlara ek olarak mekânın imgesel boyutunda imgelenebilirlik, okunabilirlik, bellek, psikolojik erişim, korku bileşenleri yer almaktadır (Montgomery, 1998). Bu bileşenlerden de anlaşılacağı üzere planlama ve tasarım süreçleri bireyin ihtiyaçları üzerinden ele alınır, değerlendirilir.

Maslow'un ihtiyaçlar hiyerarşisine göre (1954, s.39-40), bireyin yiyecek ve su gibi temel fizyolojik ihtiyaçlarından sonra ikinci temel ihtiyacı olarak güvenlik ve emniyet karşımıza çımmaktadır. Güvenlik, istikrar, bağımlılık, korunma, korkudan kurtulma, kayg1 ve kaostan kurtulma, düzen, hukuk, sınırlar ve güç ihtiyacı, çoğunlukla fizyolojik ihtiyaçları olan toplumun güvenlik ihtiyaçlarıdır. Bu bağlamda, güvenlik, öngörülebilir, yasal, düzenli dünyanın 
kesintisiz rutini veya ritim temeli gibi görülebilir (Maslow, 1954, s.39-40). Mateo-Babiano (2016) mekânda kullanıcıların ve yayaların en önemli ihtiyac1nın korunma gereksinimi olduğunun altını çizmektedir. Bunun yanı sıra, insanların sosyalleşme, eğlenme, bir arada olma gibi başka ihtiyaçları da vardır, bu da çekici ve canlı mekânlar ile mümkündür (Gehl, 1987). İnsanların kamusal alanı kullanmaları ve alandaki etkileşimleri ile ilişkili olarak, kamusal alanın kamusallığı da kendini güvende hissetmekle doğrudan ilgilidir. Güven duyulan mekânda zaman geçirmek yaya davranışının temelinde yer almaktadır. Bu nedenle, kentsel kamusal mekânların güvenli ve sosyal etkileşimleri teşvik edecek şekilde tasarlanması gerekir (Jacobs, 1961 ve Gehl, 1987 aktaran Mateo-Babiano, 2016,s.110).

Güvenlik ve emniyet, herhangi bir kentsel gelişimde yaşamsal unsurlardır. Kentlerde bireyin ve toplumun güvenlik duygusunun oluşması karmaşık bir konudur. Güvenlik veya güvende hissetme her zaman doğrudan fiili suç olayıyla ilgili değildir. İyi görünürlüğün, okunabilirliğin ve etkili aydınlatmanın olduğu yerlerde, başkaları tarafından görülebileceğimizi ve duyulabileceğimizi hissettiğimiz alanları kullanırken kendimizi rahat ve güvende hissederiz. Bu durumu dikkate alan tasarım anlayışı, herkesin refah duygusunu geliştirmede ve mekânları daha kullanıcı dostu, anlaşılması kolay ve güvenli hale getirmede önemli bir araçtır. Alanların olabildiğince çok kullanıcı grubuna açılmasına yardımcı olabilir ve sokakların ve diğer tesislerin kullanımında ortak bir güven duygusu yaratabilir (Yeang, 2000, s.106)

Güvenlik kavramı fiziksel güvenlik ve algılanan güvenlik olmak üzere iki ayrı başlık altında incelenebilir. Güvenli sokaklar, insanları yürümeye, alanı kullanmaya teşvik eder ve mekânın canlılığını artırır. Covid-19 küresel salgını öncesinde fiziksel güvenlik; mekânın fiziki öğeleri aracilığıyla kullanıcı güvenliğinin artırılmasını sağlamak amaçlı sokak genişliğinin ve kapalılığının göz önüne alınması, araç trafik hızına sınırlama getirilmesi, hız kasislerinin yollara yerleştirilmesi, yaya geçitlerinin yükseltilmesi, gerekli yerlerde yol şeritlerinin daraltılması, araç ve yaya trafiğinin kimi yerlerde ayrılması ve güvenli yaya geçitlerinin oluşturulması gibi düzenleme ve önlemler olarak siralanmaktaydı (Maslow, 1954; Southworth, 2005; Rapaport, 1987; Lambert, 2005; Jacobs, 1961; Jacobs, 1995; Appleyard, 1981; Barlas, 2006; Goodman and Trolley, 2003; Belge, 2012; Akkar Ercan ve Belge, 2016).

Algılanan güvenlik ise kullanıcının bulunduğu ortamda kendini ne kadar güvende hissettiğiyle ilgilidir. Algılanan güvenlik, kentlerin araç trafiğinin yoğunluğu, gürültü düzeyinin ve suç (vandalizm, hırsızlık, vb.) oranlarının yüksekliği, alanın ışıklandırılması ve doğal gözetlemenin (eyes on the street) 
varlığı ile ilişkilidir (Maslow, 1954; Jacobs, 1961; Whyte, 1980; Rapaport, 1987; Jacobs, 1995; Southworth, 2005; Belge, 2012; Akkar Ercan ve Belge, 2016).

Özetle, planlama, mimarlık ve sosyal bilimler yazınında güvenlik ilkesi kentsel kamusal mekân üretimi ve kullanımında algılanan ve gerçek-fiziksel güvenlik olarak ele alınmaktadır. İnsanların kamusal alanda kendilerini rahat hissetmelerini engelleyen en büyük sorunlardan biri güvenlik duygusunun olmamasıdır. Bu nedenle, uygun önlemlerle sosyal yaşam için fiziksel güvenliğin sağlanması planlama ve kentsel tasarım problemidir. Ancak, son zamanlardaki küresel salgın sürecinde fiziksel ve algılanan güvenlik kavramlarının çerçevesi değişmiştir. Küresel salgın sürecinde kamusal alan kullanımında fiziksel mesafeyi koruyarak ve bazı kısıtlamalar ile sosyalleşmenin sürdürüldüğü görülmüştür. Bu durum kamusal alanın planlanması ve tasarımında belirleyici olabilecek ilkeler içermektedir.

\section{Araştırma Yöntemi}

Araştırma kapsamında gözlem ve tespitlere dayalı olarak nicel ve nitel değerlendirmeler yapılmıştır. Güvenliğin kamusal alanda değişimi alandaki gözleme dayalıdır ve bu çalışmanın nitel kısmını oluşturmaktadır. Alanda yapılan kullanıcı sayımları ve onların Coğrafi Bilgi Sistemi (CBS) ortamına aktarılması ve mekânsallaştırılması çalışmanın nicel kısmını oluşturmaktadır. Araştırma kapsamında öncelikle kamusal alan, kentsel kamusal alan kullanımı ve kamusal alanda güvenliğe ilişkin araştırma ve yazın incelenmiştir. İkinci aşamada, örnek çalışma alanının tarihsel gelişimi de dikkate alınarak alanın nitelikleri ve küresel salgın süreci öncesindeki kullanımına ilişkin değerlendirme yapılmıştır. Daha sonra, örnek çalışma alanında kentsel-kamusal alanı incelemek ve alanın kullanımını anlamak için sosyalleşme (sosyal alanı) ve kullanıcıların örüntüleri gözlemlenmiştir. Doğrudan yapılan gözlemlerde küresel salgın öncesinde ve sürecinde farklı kullanıcı gruplarının kamusal alan kullanımında güvenlik ölçütlerine ilişkin tespitler yapılmıştır. Gözlemler sırasında farklı zaman dilimlerinde çekilen fotoğraflar ile alanın kullanımı belgelenmiştir.

Çalışmanın bir diğer aşamasında, farklı saatlerde alandaki günlük rutinleri ve ritimleri anlayabilmek için kullanıcı sayımları yapılmışır. Covid-19 küresel salgın koşulları nedeniyle uzun erimli yıllık ve/veya mevsimsel değişimlere ilişkin tespitler ve kullanıcı sayımları yapılamamıştır. Ancak günlük rutinler içerisindeki değişiklikler detaylı olarak tespit edilmiş ve CBS ortamında görselleştirilerek konumlandırılmıştır. Bu bağlamda kullanıcı sayımları ve mekânsal konumları yöntemin önemli bir parçasıdır. Her bir kullanıcı 
CBS ortamında nokta (dot/point) olarak işaretlenerek, farklı zaman dilimlerine göre ayrıştırılmıştır. Bu sayede kullanıcıların günün farklı saatlerindeki mekânsal dağılımı ve yoğunlukları temsil edilebilmiştir.

\section{Çalışma Alanı}

Türkiye'de kamusal alan kullanımı yerel politikalar ile değişmekte ve kentsel tasarım ölçütleri göz ardı edilmektedir. Mersin'de de benzer şekilde sınırlı kamu arazilerinin bulunması nedeniyle, planlama kararları ile kentlinin kullanabileceği geniş kamusal alanların ediniminde her zaman zorluklar yaşanmıştır. Bu nedenle Mersin Kıyı Parkı kentlinin ve tüm farklı kullanıcı gruplarının bir araya gelebilmesi ve sosyalleşebilmesi için tek büyük ölçekli kentselkamusal alandır. Yaklaşık 9 km uzunluğunda olan Mersin Kıyı Parkı, 20.yüzyılın başından itibaren farklı dönemlerde yapılan dolgu alanları ile biçimlenmiştir. Örnek çalışma alanı olarak belirlenen Marina ve çevresindeki kamusal alan Mersin Kıyı Parkında yer almaktadır. Marinanın inşaatına 1993 yılında Mersin'in batı kısmındaki dolgu çalışmalarının ikinci etabına başlanmış (Mersin Büyükşehir Belediyesi, 2016, s.4), 2012 yılında ise yalnızca denizcilik faaliyetleri ile birlikte alışveriş merkezi ve sosyal tesisler de dâhil olmak üzere çeşitli kentsel kullanımlar ile hizmete açılmıştr. Marinanın doğusunda 9 km'lik Mersin Kıyı Parkının tek doğal plajı yer almaktadır. Ayrıca Marina tuvalet, bebek bakım odası ve gündelik ihtiyaçların karşılanabileceği hizmetler, servisler, tesisler ve olanaklar sağlamaktadır. Bu alan küresel salgın döneminde olduğu gibi önceki dönemde de hafta içi ve hafta sonu kullanımları ile önemli bir kentsel kamusal alan konumundadır. Doğal plajın kuzeyinde ise spor alanları, rekreasyon alanları ve kaykay yapan ve paten süren gençlerin yoğun şekilde kullandığı sert zemin alanlar yer almaktadır. Çalışma alanında yer alan geniş çim alanları ise küresel salgın öncesinde ve özellikle açık alan kullanımlarının arttığı küresel salgın sürecinde kullanılan önemli bir odak oluşturmaktadır.

\section{Bulgular}

Kullanıcı sayımları, kullanım yoğunluğuna göre kamusal alanın kamusall1ğının temel belirleyicilerdir (Whyte,1980,s.73). Kullanıcı sayılarının farklı saatler içinde değerlendirilmesi, kentsel-kamusal alandaki günlük rutinleri ve ritimleri anlamamızı sağlar. Sayımlar 06:00-08:00, 08:00-10:00, 10:00-12:00, 12:00-14:00, 14:00-16:00, 16:00-18:00, 18:00-20:00, 20:00-22:00 saat aralıklarında yapılmıştır. Çalışma alanında ilk sayımlar Covid-19 küresel salgın öncesi dönemde 2019 yılının Ağustos ayında yapılmıştır. Küresel salgın döneminde 
farklılaşan kamusal alan kullanımlarını ortaya koymak amaçlı sayımlar ise Ağustos 2020 de yapılmıştır. Bu çalışma Covid-19 sürecinde insanların kamusal mekânı nasıl kullandıkları ve nasıl konumlandıklarını incelemektedir.

Gehl'in (2010) vurguladığ zorunlu aktiviteler, isteğe bağlı ve sosyal aktiviteler gibi farklı mekânsal kullanımlar değerlendirildiğinde; çalışma alanında zorunlu aktivitelerin yer almadığı görülmektedir. Çalışma alanında küresel salgın öncesi dönemde olduğu gibi isteğe bağlı (uygun zamanda ve yerde yürüme, bakma, oturma, izleme veya koşma) ve sosyal-kültürel aktiviteler (diğer insanlarla sosyalleşme bir arada etkinlik yapma) yer almaktadır. Küresel salgın dönemi öncesinde olduğu gibi sonrasında da çalışma alanı çok yoğun bir şekilde kullanılmaktadır. Alan kullanımındaki tek kısıt kamusal otoritelerin uygulamaları ve küresel salgına ilişkin kısıtlamalarla ilişkilidir. Küresel salgın dönemi öncesinde hafta sonu yapılan sayımlarda kullanıcı sayısı 984 kişidir. Küresel salgin sürecinde ise bu sayı 1052 olarak tespit edilmiştir.

Çalışma alanında yapılan sayımlar, kullanıcıların bulunduğu konuma göre CBS ortamında işaretlenmiştir. Her nokta, belirlenen zaman aralığında tek bir kullanıcıyı temsil etmektedir. Örnek şekillerde görüleceği üzere farklı zaman dilimlerine göre renklendirilen kullanıcıların mekânsal dağılımlarının karşılaştırılması mümkün olabilmiştir.

Bu bağlamda Şekil-2'de görüldüğü üzere Covid-19 küresel salgın öncesinde insanların yer seçimi belirli bir ritim ve uyum içerisinde olmamakla birlikte tek değişken yapılan aktivite ile ilişkili olarak konumlanmadır. Kişiler günlük rutinleri içerisinde spor yapma, dinlenme, balık tutma gibi farklı aktivite türlerine göre kıyı parkını kullanmaktadır. Küresel salgın öncesinde çalışma alanında festivaller düzenlenmekteydi. Alanı farklı yaş grupları ve kesimden farklı kullanıcılar kullanıyordu. Özetle, insanlar bu alanı farklı rutin ve ritimlerde aktif olarak kullanmaktaydılar. Kriz öncesinde bir arada yürüme, spor yapma, seyyar satıcıdan yiyecek alma gibi birçok aktivite ve olanaklar tereddüt etmeden özgürce kullanılmaktaydı.

Ancak, Şekil-3 ve Şekil-4'de görüldüğü üzere, küresel salgin sürecinde, yeme-içme mekânlarının sadece paket servis sağlaması, yaş gruplarına göre sokağa çıkma saatlerindeki kısıtlamalar ve maske kullanımı gibi önlemlerin yanı sıra, insanlar kendi güvenli alanlarını oluşturmuşlardır. Yaklaşık 2-9 kişilik gruplarla kendi tanıdıkları ve güvendikleri insanlar ile sosyal-fiziksel çemberlerini oluşturmuş, kentsel-kamusal alan kullanımında kendi özel alanlarını, sosyal mesafelerini tanımlamışlardır (Fotoğraf-1/2). 


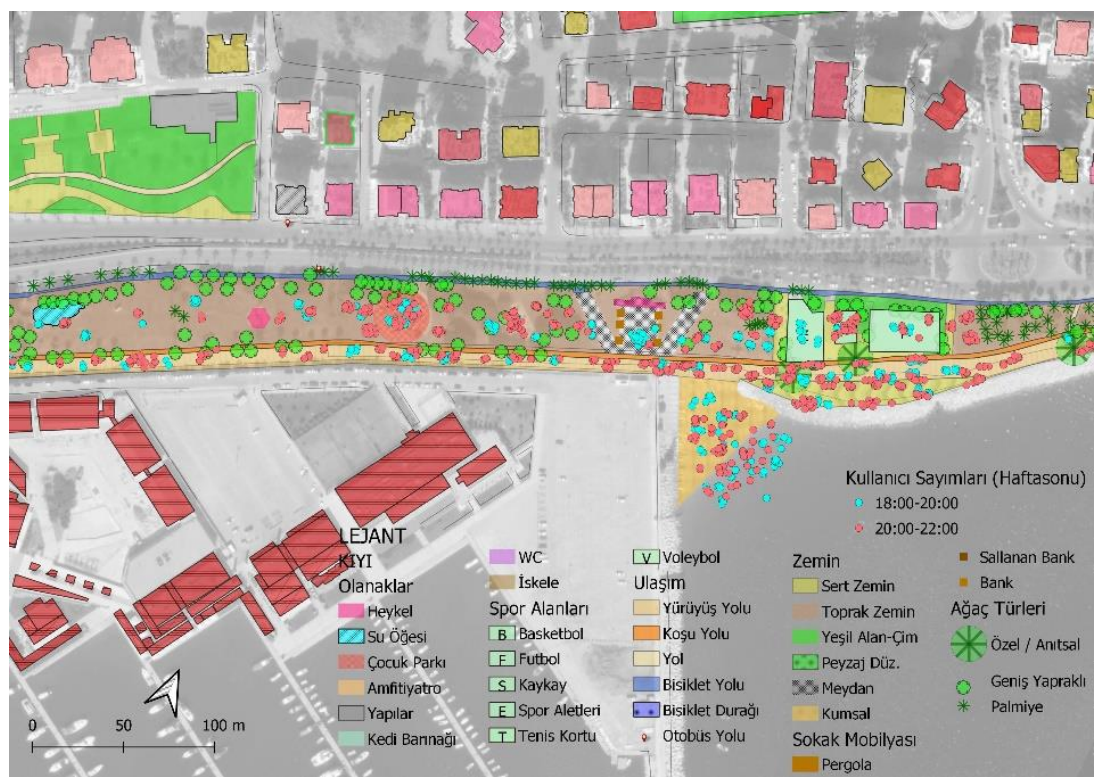

Şekil 2. Covid-19 küresel salgını öncesinde Marina kuzeyinde kalan örnek çalışma alanında akşam saatlerinde kullanıcıların mekânsal dağılımı

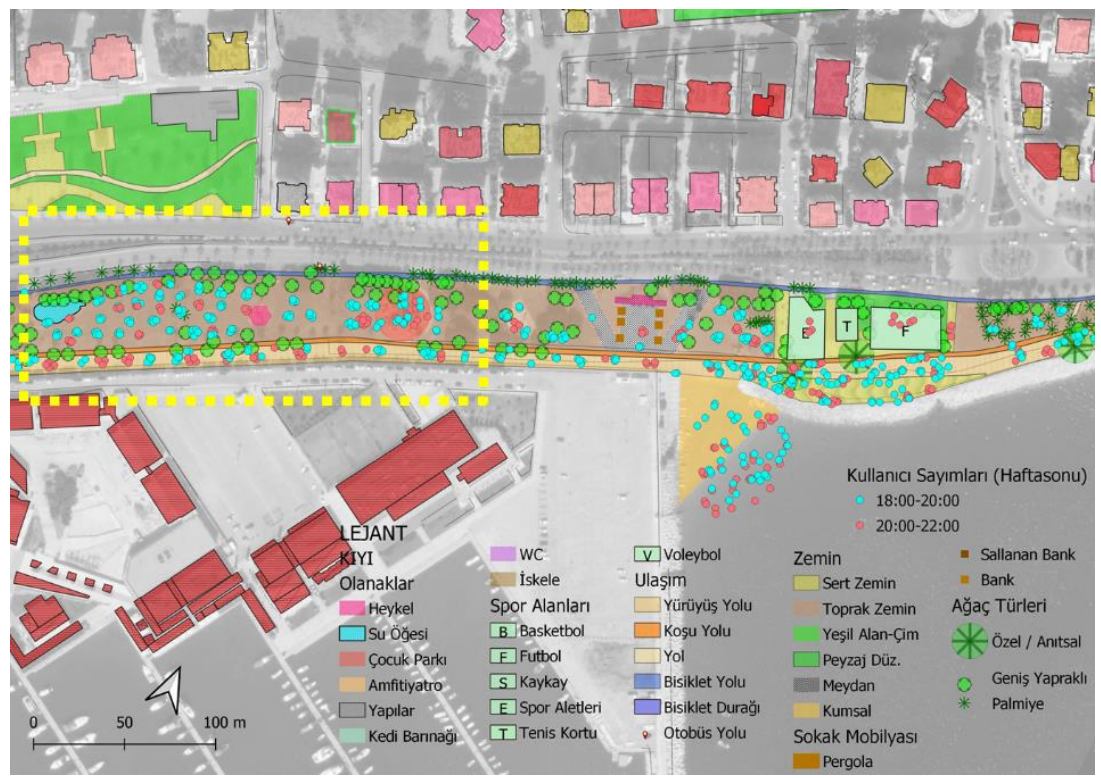

Şekil 3. Covid-19 küresel salgını sürecinde Marina kuzeyinde kalan örnek çalışma alanında akşam saatlerinde kullanıcıların mekânsal dağılımı (Sarı işaretli alan Şekil-4'de daha detaylı gösterilmiştir). 

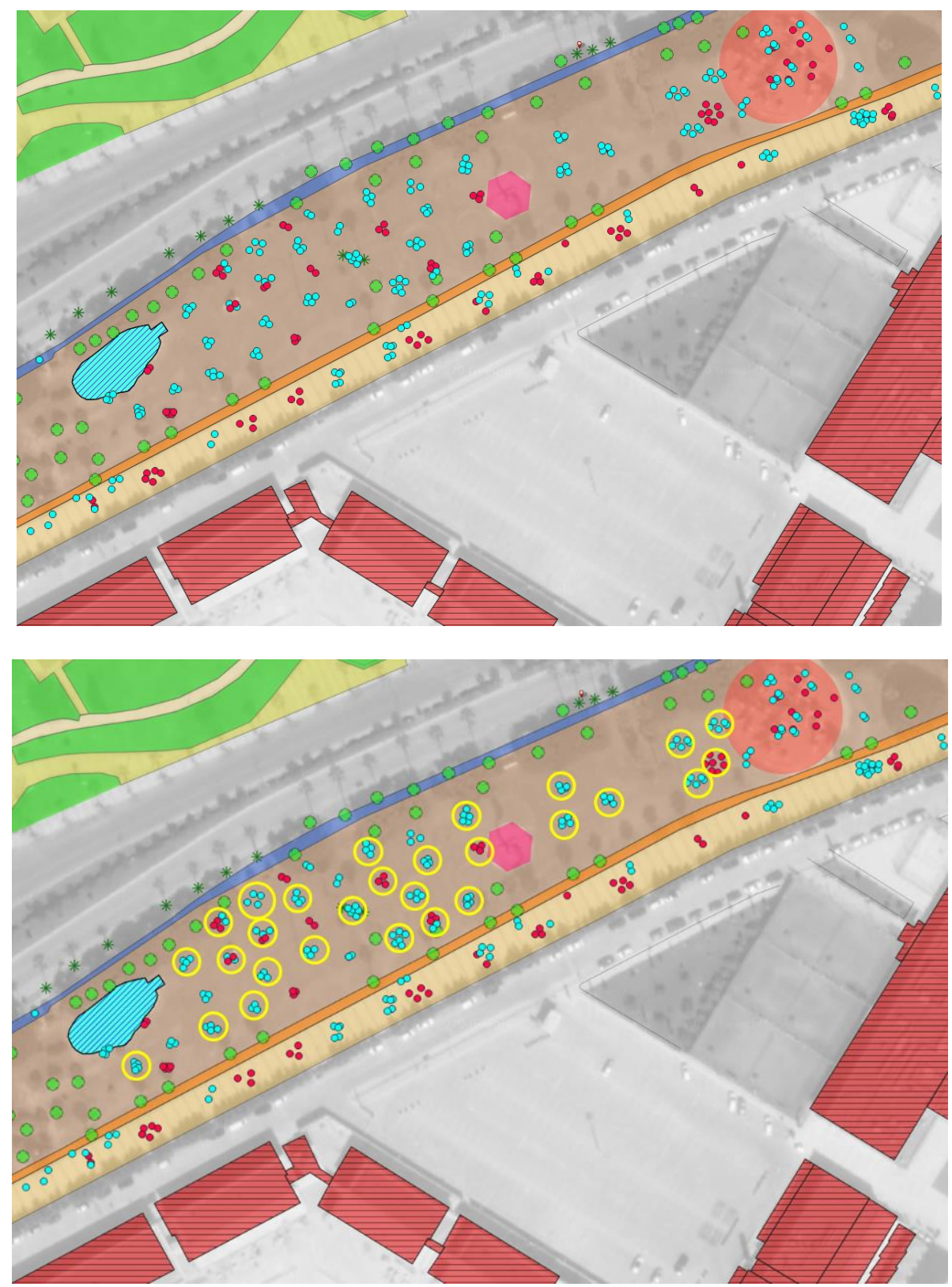

Şekil 4. Covid-19 küresel salgını sürecinde kullanıcıların mekânsal dağılımına göre oluşan fiziksel-sosyal mesafe çemberleri 


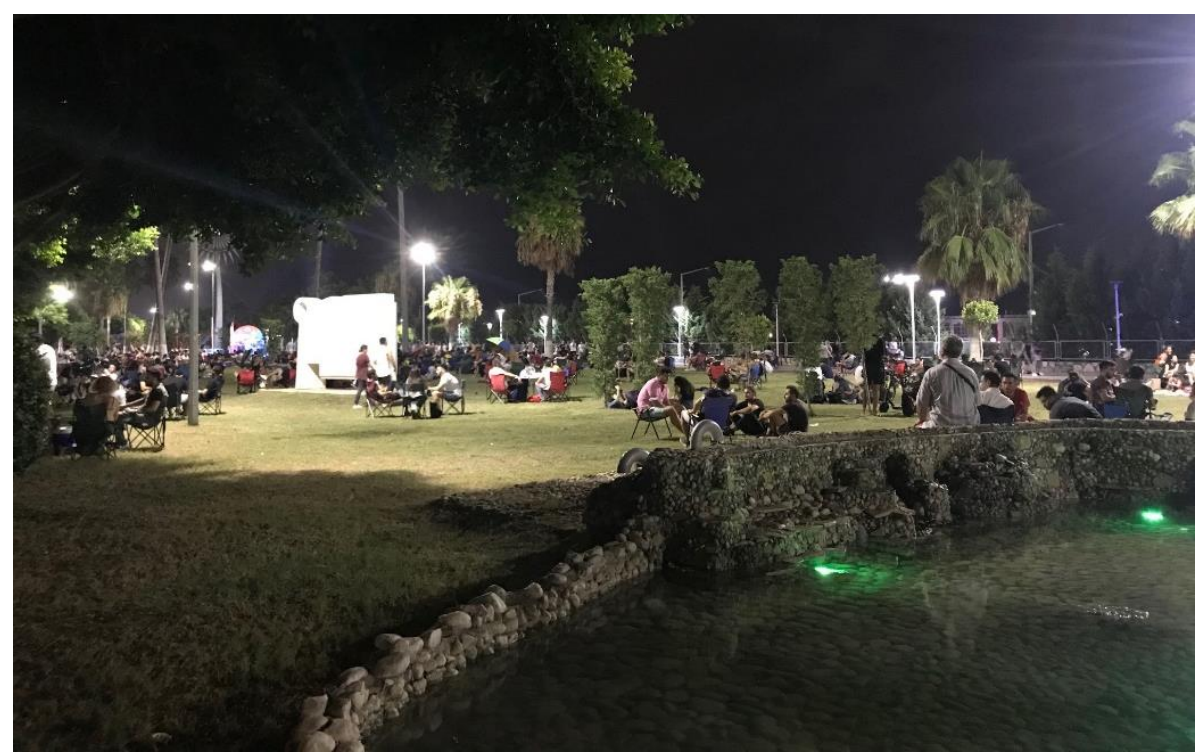

Fotoğraf 1. Covid-19 küresel salgını sürecinde örnek çalışma alanı (Yazarın kişisel arşivi)

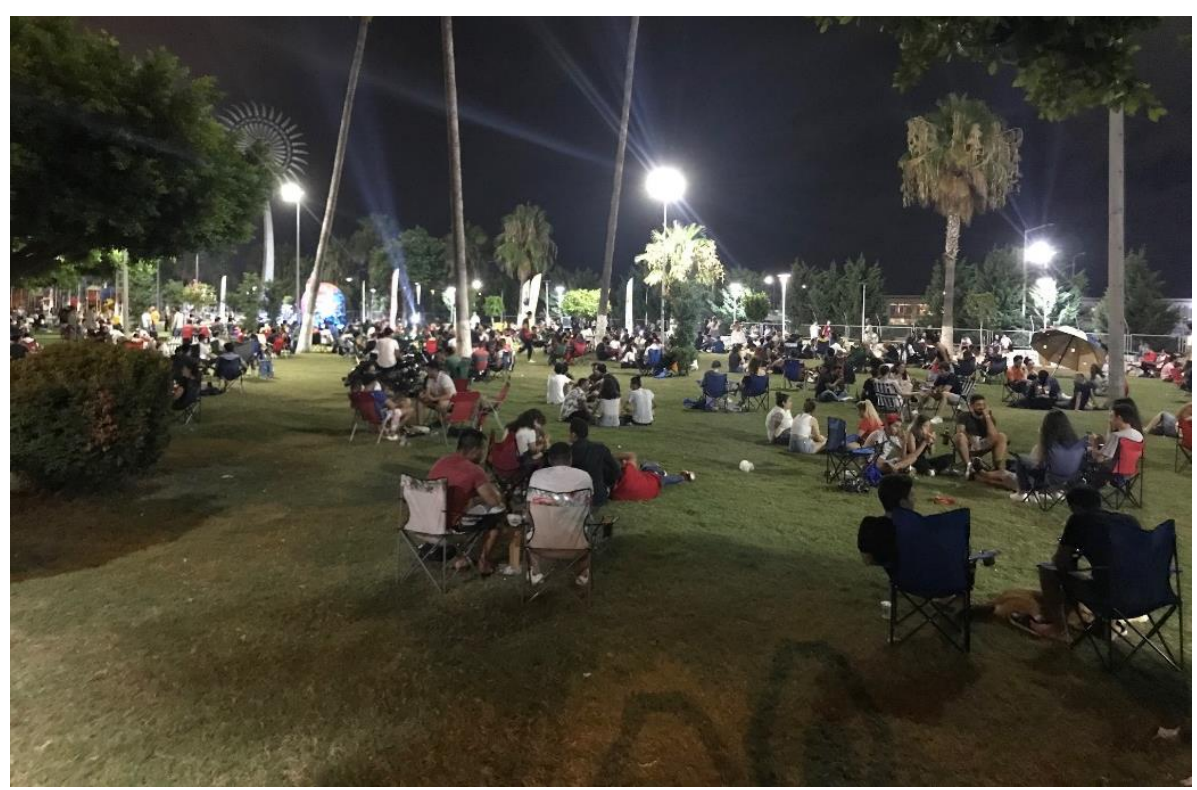

Fotoğraf 2. Covid-19 küresel salgını sürecinde örnek çalışma alanı (Yazarın kişisel arşivi) 


\section{Tartışma}

Kamusal alanın en temel tanımında toplumun her kesiminin eşit ölçüde kullanım hakkına sahip olması yer almaktadır. Küresel salgın süreci kentsel kamusal mekânları değiştirmekte ve dönüştürmektedir. Covid 19 sürecinin başında, 2020 Mart-Haziran tarihleri arasında toplum öncelikle nasıl bir durum ile karşı karşıya kaldığının farkında olmadığı ve artan vaka sayıları nedeniyle alınan önlemler çerçevesinde kamusal alanlar boş kalmıştır. Türkiye ile benzer şekilde Dünyada da kamusal alanlar hem insanların Covid-19 karşısında yaşadıkları bilinmezlikler hem de alınan önlemler nedeniyle kullanılamamıştır. İnsanın ihtiyaçlarının önemli bir parçası olan sosyalleşme, bir arada olabilme ihtiyacı (Maslow, 1954) ile ilişkili olarak, insanlar krizle yaşamaya yönelik çözümler üretmişlerdir. Bu durum zamanla kentlilerin kamusal alanı kullanma biçimlerini değiştirmiştir. Çünkü insan doğasında bir arada olma, sosyalleşme ve etkileşim içinde olma gereksinimi bulunmaktadır. Böylece toplum kendi güvenli kamusal alanını oluşturmaya başlamıştır. Yeni oluşan kamusal alan daha eşitlikçi, demokratik, yaşanabilir, insan odaklı ve yaya dostu bir kamusal alan olarak karşımıza çıkmaktadır. Örnek çalışma alanında da görüldüğü üzere, toplumun farklı kesimlerinden ve yaş gruplarından kullanıcılar kamusal alanı eşitlikçi bir biçimde kullanmaya başlamışlardır. Özetle yeni koşullara uygun olarak toplumsal yaşam biçimleri değişmekte ve dönüşmektedir.

Covid-19 küresel salgın süreciyle ortaya çıkan kentsel kriz, kentlerin ve kamusal alanların; tasarım, bakım-onarım ve yönetim açısından eksikliğini ortaya koymuştur. Kentsel kamusal mekânların üretiminde temel ilkelerden olan erişilebilirlik, eşitlik, dengeli hizmet ve olanak dağılımı, esneklik ve dayanıklılık açısından kentler küresel salgın krizine hazırlıksız yakalanmıştır.

$\mathrm{Bu}$ zorlu süreçte merkezi ve yerel otoriteler insanları güvenlikleri konusunda bilinçlendirmek için uyarılar yapmış ve farklı düzenlemeler ile bilinçlenmeyi desteklemiştir. İnsanlar sosyal mesafe, maske kullanımı, kişisel temizlik ve tesislerin güvenli kullanımı konusunda sürekli olarak sosyal ve basılı medyada olduğu kadar el ilanları ve bilgi afişleriyle de uyarılmıştır. İnsanlar da mümkün olduğu ölçüde kişisel önlemlerini geliştirmiştir. Örneğin, insanlar yürürken diğer insanların konumlarına göre mesafelerini ayarlamaya başlamışlar veya maskesiz olan insanlardan uzakta kalmaya dikkat etmeye çalışmışlardır. Örnek çalışma alanında da görüldüğü üzere, kullanıcılar kendi grupları ile yakınlaşarak, sandalyeleri ya da güvenli sınırlarını oluşturan piknik örtüleri ile güvenli alanlarını çizmeye ve belirlemeye başlamışlar- 
dır. Bu durum dikkate alınarak Dünya'da ve Türkiye'de de örneklerini gördügüumüz güvenlik çemberleri çizilmiştir. Ancak, örnek çalışma alanında da görüldüğü üzere, insanlar kendi hayali çizgilerini çizmişlerdir. Oluşan hayali çemberler grupların büyüklüğüne göre değişmektedir. Gruplar arasındaki mesafeye ilişkin belirli bir mesafe bulunmamakla birlikte, tavsiye edilen 1,52 metre sosyal mesafenin korunmaya çalışıldığı görülmektedir. Ayrıca kalabalık ortamlarda bulunmamaya ve kapalı ortamları kullanma sürelerini sınırlandırmaya çalışmışlardır. Bu durum güvenlik ölçütünde insanların kendilerini iyi ve güvende hissedebilmeleri için yeni bir takım davranış değişikliklerini beraberinde getirdiği gözlemlenmiştir. Kamusal alanda kullanıcı davranışları küresel kriz ile değişerek dönüşmektedir.

Kentsel mekândaki hareketliliğin, yürünebilirliğin, alan kullanımının artması o alanın kamusallığı ile ilişkilidir. Yürüme, kamusal alanın kamusallığını ve yaşanabilirliğini sürdürür (Solnit,2000,s.256). Jacobs (1961) sevilen ve sık kullanılan bir caddenin sadece çok sayıda insanın orada gidip gelmesi, o alanı kullanması sayesinde suç unsurlarından nasıl korunduğunu dile getirmiştir (Jacobs, 1961 aktaran Solnit, 2000). Böylece insanlar hareketli ve aktif bir caddede kendilerini güvende hissedebilirler.

Kentsel krizlere hazırlıklı olmanın temelinde kentsel dayanıklılık gelmektedir. Bu bağlamda sorulması gereken temel soru, tüm kamusal alanların, sahiplik veya kapsayıcılık açısından herkes tarafından etkin bir şekilde erişilebilir ve kullanılabilir olup olmadığıdır? Yalnızca Covid-19 küresel salgın sürecinde değil kentsel kamusal mekânların gerekli düzenlemeler ve uygun politikalar ile krizler için yeniden ele alınması, bu bağlamda her yere özgü, yerin karakterine ve özelliklerine uygun kentsel kodların oluşturulması ve tüm tasarım, planlama ve yenileme süreçlerinin bu kodlar ile geliştirilmesi gereklidir. Böylece hem krizlere maruz kaldığında yeni duruma adapte olabilen, uyumlanabilen hem de yere özgü tasarım süreci gerçekleştirilebilecektir.

\section{Sonuç}

Öngörülebilir, yasal, düzenli ve emniyetli bir çevrede/dünyada belirli günlük ritme dayanan güvenlik bileşenleri vardır, bu da kamusal alanlar gibi fiziksel olarak güvenli/emniyetli yerlerde güvenliği algılamak anlamına gelmektedir. Bununla birlikte, kamusal alanın kamusallığı, bireyin kendisini güvende hissetmesi ile doğrudan ilgilidir. Bu bağlamda, güvenlik, gerçek (fiziksel) ve algılanan biçimleriyle kamusal alan üretiminde ve mekânın kamusallı̆ı̆nda önemli bir parametredir. Güvenlik duygusunun eksikliği, insanların kamusal alanda kendilerini rahat hissetmelerini engelleyen en temel kentsel problemlerden biridir. 
Bu nedenle, temelde alınması gereken önlemler ve uyulması gereken kurallarla toplumsal yaşam için fiziksel güvenlik bir planlama ve kentsel tasarım sorunsalıdır. Ancak, küresel salgın sürecinde karşılaşılan durum, bizi fiziksel mesafeyi koruyarak ve bazı engellerle sosyalleşmeye zorlamaktadır. Bu durum ise toplumsal yaşamı ve günlük rutinleri, gündelik hayatı kontrol ederek kamusal alan özgürlüğü konusunda bir ikilem ortaya çıkarmaktadır. Öte yandan, küresel salgın koşulları, toplu taşıma, kamuya açık alanlara ulaşım gibi uygun ve erişilebilir kamu hizmetlerinin gerekliliğine işaret etmektedir.

Covid 19 küresel salgını ile kentsel kamusal alanların insanlar için ne kadar önemli ve değerli olduğu görülmüştür. Özellikle küresel salgın sürecinde, parklar ve meydanlar gibi kamusal alanların değişen kullanımlarıyla ilgili deneyimler, plancılar ve kentsel tasarımcılar için yeni bir tartışma konusu ortaya koymaktadır. Kentsel kamusal mekânların krizlere hazırlıklı olup olmadığı, yukarıda da belirtildiği üzere, en önemli sorudur. Günümüzdeki küresel salgın gibi gelecekte de, başka kentsel krizlerin olacağı öngörülmektedir. Bu durumda, kentsel krizler için kentsel kamusal alanlar nasıl planlanmalı ve/veya yeniden nasıl tasarlanmalıdır?

Covid-19 öncesinde, sürecinde ve gelecekte sonrasındaki günlük rutinlerin ve kullanımların karşılaştırması bizi planlama ve kentsel tasarım stratejileri geliştirebilmemiz için yönlendirebilir.

Bu ölçütler, sosyal mesafeyi korumak için tanımlanabilecek fiziksel mesafe koşulları olduğu kadar, kişilerin kendi başlarına ve/veya tanıdıkları kısttlı çevreler ile sosyalleşebilmesi için uygun mekân tasarımlarının geliştirilmesi anlamına gelmektedir. Covid-19 küresel salgını kentsel açık alanların hava dolaşımını sağlayacak şekilde sürekliliğinin önemini bir kez daha ortaya koymuştur. Bu durumda, kentsel planlamada mevzuat hükümlerinde de yer almaya başlayan yürüme mesafeleri dikkate alınarak kentlinin erişebileceği kamusal alanların belirlenmesi en temel planlama ilkelerinden biridir. Daha alt ölçeklerde ise, kentsel tasarım ilkeleri dikkate alınarak kentliye alternatif kullanım olanakları sunulmalıdır. Öte yandan kentsel-kamusal mekânların şehre ve insana kattı̆̆ kazanımlar korunmalıdır. Sonuç olarak, kentsel-kamusal mekânların planlanmasında ve tasarımında bireyler veya küçük gruplar arasındaki sosyal mesafe koşulları dikkate alınarak güvenlik kavramının kapsamı yeniden değerlendirilmelidir. Bireylerin ve/veya küçük grupların kamusal alanı sosyal mesafe koşullarını dikkate alarak kullanabilmesi için farklı esneklikler sağlayacak şekilde kentsel tasarım önerileri geliştirilebilir. Güvenlik ölçütlerinden bir tanesi de kentsel sağlıktır. Sağlıklı kent- 
lerin genişleyen çerçevesi içerisinde, temiz hava ve kamusal mekânın sağlanabilmesi için hava dolaşımı kadar güneş ışığının kullanımı da önemlidir. Bu noktada, kentsel tasarımda sokak mobilyaları ve/veya zeminde uygun teknolojiler ile geliştirilmiş malzeme kullanımları da sağlanmalıdır.

Yapılan araştırma, küresel salgın öncesi ve sonrası kullanıcıların mekânsal dağılımının karşılaştırılması yöntemi kullanılarak kriz dönemi ile değişen kamusal mekânların üretiminde güvenlik parametresinin değişimini ortaya koymuştur. Bu durumda, yerelin özelliklerinin de farkında olunması, gerekirse yerel tasarım indekslerinin geliştirilmesi ile her yer için alana özgü kent kodlarının üretilmesi ve özgün planlama ve kentsel tasarım stratejilerinin geliştirilmesi mümkün olabilecektir. Bu şekilde üretilen mekânlar toplumun ihtiyaçlarına cevap vererek yaşanabilir, dayanıklı, yere özgü ilkelerini içinde barındırabilecektir.

Sonuç olarak, küresel salgın süreci öncesinde değişen-dönüşen kamusal alan tartışmalarında yer alan alışveriş merkezi, kafeler ve diğer yeme-içme mekânları yerine küresel salgın sürecinde kamusal açı alanların sokaktan başlayarak meydan ve parklara kadar daha fazla ve yoğun kullanılma talebinin ortaya çıktığı görülmektedir. Bu durumda, kamusal alanların planlaması ve tasarlanmasına yönelik sağliklı kent stratejilerinin mahalle ölçeğinden başlayarak farklı ölçeklerdeki kamusal alanlara uzanması önem taşımaktadır.

Covid 19'un mekânsal dağılımı aynı zamanda sosyal bir ayrışmayı ve eşitsizlikleri de göstermektedir. Küresel salgın sürecinin en temel mottolarından olan insanların evde kalması yönündeki önlemler, özellikle müstakil evi, bahçesi, ya da kapalı sitede yeşil alanı olan, balkonu olan, balkonsuz, kotta yaşayan insanlar arasındaki konut eşitsizliğini de ortaya koymuştur. Bu durum mekân tasarımcılarını iç ve dış mekânların krizlere hazırlıklı bir şekilde dönüştürülmesi ve değiştirilmesi gerçeği ile yüzleştirmiştir. Türkiye'nin gündeminde olan kentsel dönüşüm süreçlerinde de küresel krizin etkileri ve öğrettikleri dikkate alınarak kamusal alanlar üretilmelidir.

Covid 19 küresel salgin süreciyle krizlere hazırlıklı bir mekân üretimine doğru gidilmektedir. Bu durum kent merkezlerinin, alışveriş yapılan caddeleri, alışveriş merkezlerini, restoranları ve kafeler gibi kapalı mekânların yeniden açık alanlar ile tasarlanarak yeni bir iç-dış mekân tasarımı gerekliliğini ortaya koymuştur. Yeniden değişim sürecinde yere özgü tasarım ile kent kodları üretilmeli ve her yere uygun olarak bir tasarım geliştirilmelidir. Küresel salgın süreci sonlandığında veya kontrol altına alınabildiğinde, kullanıcı davranışlarına ilişkin daha detaylı araştırma ve tespitler yapılabilecektir. 


\title{
Extended Abstract
}

\section{Changing Perception of Safety in Urban Public Space during Covid-19 Pandemic}

\author{
Züleyha Sara Belge \\ ORCID: 0000-0003-0500-4847
}

Public space belongs to the whole community and is mostly freely used by everyone. Experience of being an individual in the public space is gained through daily practices, routines and social life. Considering the changing and diversifying needs of contemporary society today, the concept of public space has expanded. The expansion that started with the use of open and closed areas of shopping centres is now associated with the use of food and beverage places such as cafes and restaurants. Therefore, the concept of public space is independent of property and possessive rights. It is important not to belong to the public but to use the public space together and to be a social practice area.

The concept and perception of safety is one of the most basic criteria in the effective use of public space. According to Maslow's hierarchy of needs (1954, s. 39-40), after the basic physiological needs of the individual such as food and water, safety appear as the second basic need. Safety can be seen as the uninterrupted routine or rhythm foundation of the predictable, legal, orderly world (Maslow, 1954). Mateo - Babiano (2016) underlines that the most important need of users and pedestrians in the space is the need for protection. Besides, people also have other needs such as socializing, having fun, being together, and this is possible with attractive and lively spaces (Gehl, 1987). In relation to people's use of the public space and their interactions in the space, the publicity of the public space is directly related to feeling safe. Spending time in a safe place is at the heart of pedestrian behaviour. Therefore, urban public spaces should be designed to encourage safe and social interactions (Jacobs, 1961 and Gehl, 1987 as cited Mateo-Babiano, 2016).

In addition to physical safety criteria such as isolation from vehicle traffic and / or taking necessary precautions for the effects of vehicle traffic, reducing 
the negative effects of environmental factors (sun-shade, wind, rain, etc.) or adequacy of night lighting, the perceived effects that affect the users' feeling of safety are also defined as safety criteria. However, due to the risks and precautions posed by the Covid-19 pandemic process, changes in the concept of safety in public spaces were also observed. In addition to the restrictions on the use of open spaces, measures such as social distance, mask and hygiene and temperature measurement have also caused changes in the use of public spaces. For this reason, it would be appropriate to review the safety criteria in the public space determined before the Covid-19 pandemic period.

Within the scope of this study, a method based on observation and comparison was followed in case study area in order to evaluate the safety criteria in the public space. The Marina area of Mersin coastal park has been determined as a case study area. In this area, based on the observations made before the pandemic process, the research on the users during the pandemic enabled the changes in the perception of safety to be monitored. As a result of the study, suggestions on the formation of public space in planning and urban design were developed based on these observations and analyses.

Within the scope of the research, quantitative and qualitative evaluations were made based on observations and findings. The change of safety in the public space is based on observation in the field and constitutes the qualitative part of the study. User counts in the field and their transfer to the Geographical Information System (GIS) environment and their spatialization constitute the quantitative part of the study. In another phase of the study, user counts were made in order to understand the daily routines and rhythms in the field at different times. Due to the Covid-19 pandemic conditions, longterm annual and / or seasonal counts could not be made. However, the changes in daily routines were determined in detail and visualized and positioned in the GIS environment. In this context, user counts and spatial locations are an important part of the method.

Before the Covid-19 pandemic, people's choice of location was not in a certain rhythm and harmony, but the only variable was positioning in relation to the activity. People use the coastal park according to different types of activities such as sports, recreation and fishing in their daily routines. Moreover, festivals were held in the coastal park before the pandemic. However, during the pandemic process, people have created their own safe areas in addition to measures such as the food and beverage places providing only package service, curfews according to age groups and the use of masks. They formed their social-physical circles with people they know and trust with groups of 
approximately 2-9 people, and defined their own private spaces and social distances in the use of urban-public spaces.

In this difficult process, central and local authorities made warnings to raise awareness of people about their safety and supported awareness with different regulations. People are constantly warned about social distance, use of masks, personal hygiene and safe use of facilities by flyers and information posters in social and print media. $\mathrm{S} /$ he has developed personal precautions as much as possible in humans. For example, people have begun to adjust their distance according to other people's positions while walking or have tried to be careful to stay away from people without masks. In addition, they tried not to be in crowded environments and to limit the time of using indoor environments. This situation has brought about a new set of behavioural changes in order for people to feel good and safe in the safety criterion. User behaviours in the public space have changed and transformed with the global crisis.

With the Covid 19 pandemic, it has been seen how important and valuable urban public spaces are to people. Experiences with the changing uses of public spaces such as parks and squares, especially during the pandemic process, raise a new debate for planners and urban designers. Whether urban public spaces are prepared for crises is the most important question, as stated above. It is obvious that there will be other urban crises in the future, as in the current global epidemic. So, how should urban public spaces be planned and / or redesigned for urban crises.

\section{Kaynakça/References}

Akkar, M. (2005). The changing 'publicness' of contemporary public spaces: A case study of the Grey's Monument Area, Newcastle upon Tyne. Urban Design International. 10: 95-113.

Akkar Ercan, M. (2012). Kamusal mekân. Melih Ersoy (Der.) Kentsel Planlama Ansiklopedik Sözlük içinde. (ss.175-178), İstanbul, Ninova Yayınları.

Akkar Ercan, M., \& Memlük, N. O. (2015). More inclusive than before? The tale of a historic urban park in Ankara, Turkey. Urban Design International, 20(3), 195-221.

Akkar Ercan, M., \& Belge, Z. S. (2016). Daha yaşanabilir kentler için mikro ölçek bir yürünebilirlik modeli, METU Journal of the Faculty of Architecture, 34(1).

Appleyard, D. (1981). Livable streets, University of California Press, Berkeley, CA.

Barlas, A. (2006). Urban streets and urban rituals, ODTÜ Yayınları, Ankara.

Belge, Z.S. (2012). Increasing walkability capacity of historic city centres: the case of Mersin. (Yayımlanmamış yüksek lisans tezi). ODTÜ, Ankara, http://etd.lib.metu.edu.tr/upload/12614768/index.pdf 
Bilsel, F.C. (2009). Yeni dünya düzeninde çözülen kentler ve kamusal alan: İstanbul'da merkezkaç kentsel dinamikler ve kamusal mekan üzerine gözlemler, Eylül 2018 tarihinde https://kendineaitbiroda.wordpress.com/2009/08/01/yeni-dunya-duzeninde-cozulen-kentler-ve-kamusal-alan-istanbulda-merkezkac-kentsel-dinamikler-ve-kamusal-mekan-uzerine-gozlemler-yazar-cana-bilsel/ adresinden erişildi.

Carmona M., De Magalhaes C. and Hammond L., (2008) Public space, The Management Dimension, Routledge.

Gehl, J. (1987). The life between buildings. New York: Van Nostrand Reinhold.

Gehl, J. (2010). Cities for people, IslandPress, Washington\&Covelo\&London.

Goodman R., \& Tolley R., (2003). The decline of everyday walking in the UK: explanations and policy implications, Sustainable transport, Planning for walking and cycling in urban environments içinde. (Der. Rodney Tolley) Woodhead Publishing Ltd.

Jacobs, J. (1961). The death and life of great American cities. New York: Vintage.

Jacobs, A. B. (1995). Great streets. Cambridge, Massachusetts: MIT Press

Lambert, K., (2005). A critical evaluation of livability in Garrison Woods, (Yayımlanmamış yüksek lisans tezi), University of Calgary, Calgary

Lefebvre, H. (1991). Critique of everyday life: Foundations for a sociology of the everyday (Vol. 2). Verso

Lefebvre, H. (2014). Mekânın üretimi, İstanbul.

Maslow, A. H. (1954). Motivation and personality. New York: Harper and Row.

Mateo-Babiano, I. (2016). Pedestrian's needs matter: Examining Manila's walking environment. Transport Policy, 45, 107-115.

Mersin Büyükşehir Belediyesi (2016) Müftü Deresi ve çevresi kentsel dönüşüm ve gelişim projesi geliştirilmesine yönelik fizibilite raporu.

Montgomery, J. (1998). Making a city: Urbanity, vitality and urban design, Journal of Urban Design, 3:1, 93-116

Nasar, J. L. (1989). Perception, cognition, and evaluation of urban places. Public places and spaces içinde (pp. 31-56). Springer, Boston, MA.

Rapaport, A. (1987). Pedestrian street use: Culture and perception: Public street for public use, McMillan, Agincourt Ontario, Canada.

Solnit, Rebecca (2016), Yol aşkı: Yürümenin tarihi, (çev. Elvan Kıvılcım), İstanbul: Encore Yayınevi.

Southworth, M. (2005). Designing the walkable city, Journal of Urban Planning and Development, 131:4, Aralik, 246-257.

Whyte, W. (1980). The social life of small urban spaces. Washington: The Conservation Foundation.

Yeang, L. D. (2000). Urban design compendium. English Partnerships/Housing Corporation, London. 